International Journal of Artificial Intelligence \& Applications (IJAIA) Vol. 6, No. 4, July 2015

\title{
FUZZY CONTROLLER AND NEURAL ESTIMATOR APPlied TO CONTROL A SYSTEM POWERED BY THREE-PHASE INDUCTION MOTOR
}

\author{
Élida Fernanda Xavier Júlio ${ }^{1}$, Simplício Arnaud da Silva ${ }^{2}$, Cícero da Rocha Souto ${ }^{3}$ \\ and Isaac Soares de Freitas ${ }^{4}$ \\ ${ }^{1}$ Postgraduate Program in Mechanical Engineering, Federal University of Paraíba, João \\ Pessoa, PB, Brazil \\ ${ }^{2}$ Department of Electrical Engineering, Federal University of Paraíba, João Pessoa, PB, \\ Brazil \\ ${ }^{3}$ Department of Electrical Engineering, Federal University of Paraíba, João Pessoa, PB, \\ Brazil \\ ${ }^{4}$ Department of Electrical Engineering, Federal University of Paraíba, João Pessoa, PB, \\ Brazil
}

\begin{abstract}
In this study, a control strategy is presented to control the position and the feed rate of a table of a milling machine powered by three-phase induction motor, when machining pieces constituted by different types of materials: steel, brass and nylon. For development of the control strategy, the vector control technique was applied to drive the three-phase induction machines. The estimation of the electromagnetic torque of the motor was used to determine the machining feed rate for each type of material. The speed control was developed using fuzzy logic Takagi-Sugeno (TS) model and the estimation of the electromagnetic torque using the artificial neural network (ANN) of the least mean square (LMS) algorithm type. The induction motor was fed by a three-phase voltage inverter hardware driven by a digital signal processor (DSP). Experimental results are presented.
\end{abstract}

\section{KEYWORDS}

Position Control, Feed Rate Control, Estimated Electromagnetic Torque, Fuzzy Logic, Artificial Neural Networks

\section{INTRODUCTION}

Milling is a machining process which consists of removing material from a piece, in order to construct flat surfaces or with a certain form. The removal of material is performed intermittently by the combination of two movements performed simultaneously: the rotation of the cutter around its axis and the linear movement of the milling machine table where the piece to be machined is fixed [1].

In many of machining systems, constant values of feed rate and cutting speed are established throughout the tool path in the machining of surfaces, which can be very expensive for manufacturers [2]. 
Cutting parameters for machining should be monitored and adjusted automatically by selecting them appropriately to the machining process, especially the parameters of feed rate and cutting speed [3, 4]. In the work [5], an algorithm to adjust the feed rate automatically was developed with the goal of achieving maximum productivity in machining of a manufacturing line.

Difficulties as the geometric complexity of pieces, high hardness and roughness of materials are identified in the machining of free and complex formats of surfaces. In these cases, the best method to control the occurrence of impacts is to regulate and control the cutting parameters according to the shape and the surface structure.

One of the effective ways to improve CNC machining efficiency is to use optimal cutting parameters. An optimization method of cutting parameters for machining free formats of surfaces was developed by applying the adaptive control of the feed rate in [6].

Due to the need of machining systems that would provide drives with variable speed, milling machines have increasingly been driven by three-phase induction motors. Such motors are widely used due to their low cost, ability to operate with a variety of loads in adverse conditions, simplicity of construction and maintenance.

In three-phase induction motor, the implementation of vector control for direct field orientation allows that the position of the flux is determined by measuring the magnitudes of stator terminals: voltage and current [7].

Control strategies for milling can be developed through programming algorithms with application of intelligent controllers and estimators, using fuzzy logic and artificial neural network. The fuzzy and ANN techniques deal with nonlinearities easily, enable the control of complex multivariable systems and dispense mathematical modeling of the processes.

A methodology using ANN associated to fuzzy logic was presented in thesis [8] for construction of a machining process controller, because of analytical complexity and non-linear responses of this machining system.

Fuzzy logic enables the implementation of human experience in systems. The Takagi-Sugeno fuzzy model is able to represent, approximate or exact shape, any nonlinear dynamics as a combination of locally valid linear models, by interpolating smoothly [9]. The TS fuzzy technique combines a fuzzy rule-based method and a mathematical method, using conditional propositions, whose antecedents and consequents are linguistic variables and linear equations, respectively [10].

A fuzzy control strategy for end milling process was presented in [11]. In this work, the fuzzy controller was implemented adaptively aiming to maximize the feed rate for a slow machining of complex shapes surfaces.

In the research [12], a fuzzy approach was developed to determining the optimum feed rate for the geometric features of a piece to be milled.

The artificial neural network is a technique organized according to human neural structure, which acquires knowledge through a learning process, with parallel and adaptive processing [13].

The LMS learning algorithm is an ANN of error minimizing, based on instant estimations of error in the output [14]. In the first work of great relevance applying LMS algorithm [15], the interference cancellation using adaptive filters was an important reference in the field of signal digital processing. 
The LMS algorithm technique was used to develop an adaptive filter for reducing and eliminating noise of interference signals in frequency radio at work [16], due to the simplicity of implementation and low computational complexity of this algorithm.

In reference [17], estimation of the electromagnetic torque of a three-phase induction motor was obtained by applying the LMS algorithm. For this, neural adaptive filters were developed to eliminate offsets in the estimation of the stator flux.

The machining system developed for the realization of this work has a vertical milling machine. The table of the milling machine is composed of two bases, one called $\mathrm{X}$ base and the other $\mathrm{Y}$ base, powered by three-phase induction motors. In this work, the drive and control of the $\mathrm{X}$ base was performed in the machining process of materials: steel, brass and nylon.

The objectives of this work are: trigger the system with specific feed rates for cutting each material; control the position and the feed rate of the $\mathrm{X}$ base of the milling machine table, in the machining process of pieces constituted by different types of materials, called specimens. The rotation of the cutting tool is constant in this process.

A speed controller using the TS fuzzy model is developed to control the feed rate of the X base. The estimation of the electromagnetic torque of the motor of this base is performed using ANN of the LMS algorithm type. A DSP is programmed to implement the control strategy of the machining system.

\section{DEVELOPMENT OF THE SYSTEM}

The vertical milling machine of machining system is shown in Figure 1 whose cutting tool is an end mill. The $\mathrm{X}$ base (upper base) of the milling machine table has a course of $200 \mathrm{~mm}$. On this base, the specimens that were submitted to the frontal machining processes were fixed.

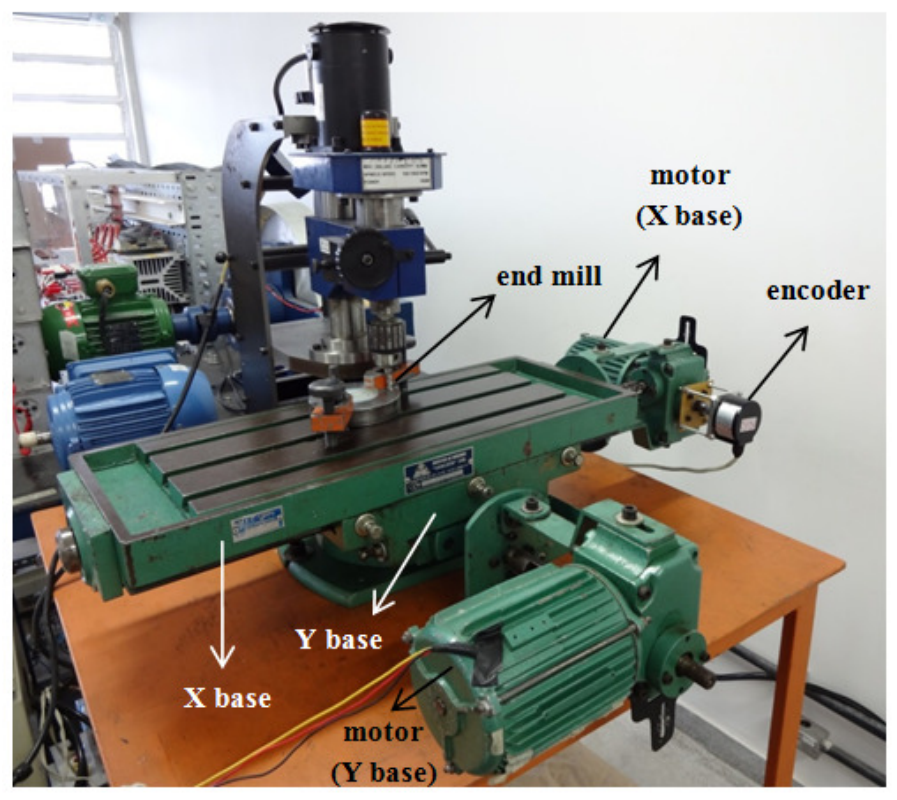

Figure 1. Vertical milling machine 
Two types of specimens were prepared, i.e., a specimen constituted of steel and brass, and the other constituted of steel and nylon.

The machining of a specimen generates the imposition of load to the induction motor of the $\mathrm{X}$ base. Therefore, the electromagnetic torque of this motor is estimated, in order that through this estimation be verified the type of material machined. Thus, the specific feed rates are applied to machining each type of material of a specimen from the signal of the estimated electromagnetic torque.

As the pitch of the $\mathrm{X}$ base trapezoidal spindle is $4 \mathrm{~mm}$ and a complete revolution of the motor shaft corresponds to $2 \pi \mathrm{rad}$, a numerical factor of $0.032 \mathrm{~mm} / \mathrm{rad}$ was obtained. The position of $\mathrm{X}$ base is determined from multiplying the angular position of rotor of the motor by $0.032 \mathrm{~mm} / \mathrm{rad}$; as well as, the feed rate of this base is obtained by multiplying the rotational speed of the rotor by this numerical factor.

In Figure 2, the system configuration for the drive and control of the $\mathrm{X}$ base of the milling machine table is schematized. In this diagram, are presented: the digital signal processor, used in the processing, transmission and data acquisition; the hardware constituted by three-phase voltage inverter, which feeds the three-phase induction motor of the $\mathrm{X}$ base; the encoder for measuring the angular position and rotational speed of rotor of the motor, thereby obtaining the position and feed rate of the X base; and Hall effect sensors, used to obtain the currents and voltages of the motor stator.

Besides the electrical and electronic components, in Figure 2, are represented: the control system, developed for drive and control the $\mathrm{X}$ base of the milling machine, and the estimation system of the electromagnetic torque of the motor of this base.

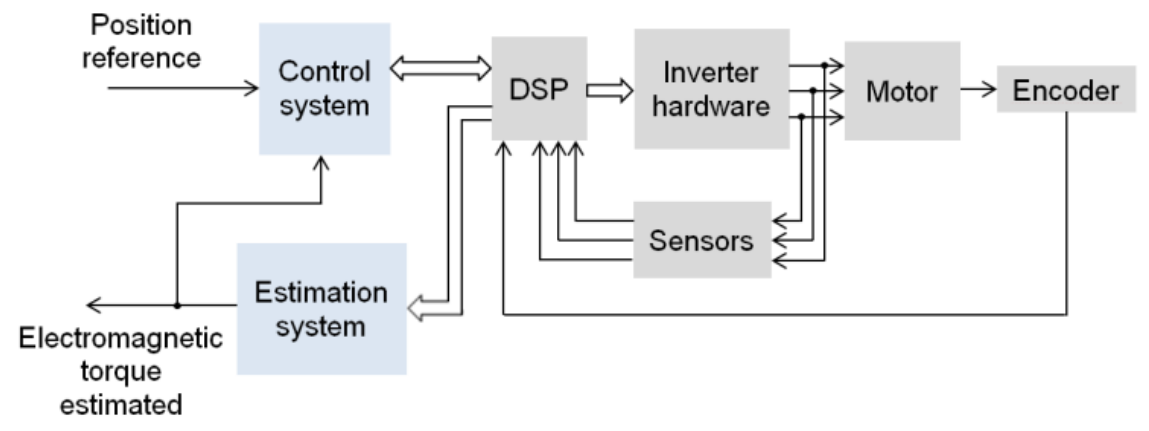

Figure 2. Schematic diagram for control the $\mathrm{X}$ base of the milling machine

\subsection{Control System}

The control system of the milling machine was developed in closed loop, controlling the threephase induction motor of the $\mathrm{X}$ base. For this, a current controller using a proportional-integral (PI) controller, and a speed controller using a TS fuzzy model were developed.

The speed controller consists of: a fuzzy PD base, TS model, with Error and Derror entries; and the Error integration. A structure of PD+I speed fuzzy controller was implemented, shown in Figure 3 , in which $i_{t s}$ is the output variable of the fuzzy PD base, $\mathrm{k}_{\mathrm{p}}$ is the gain equal to 1 and $i_{s q}^{b^{*}}$ is the control variable that corresponds to the stator current of the three-phase induction motor, in $q$ component in the referential of the rotor flux. 
International Journal of Artificial Intelligence \& Applications (IJAIA) Vol. 6, No. 4, July 2015

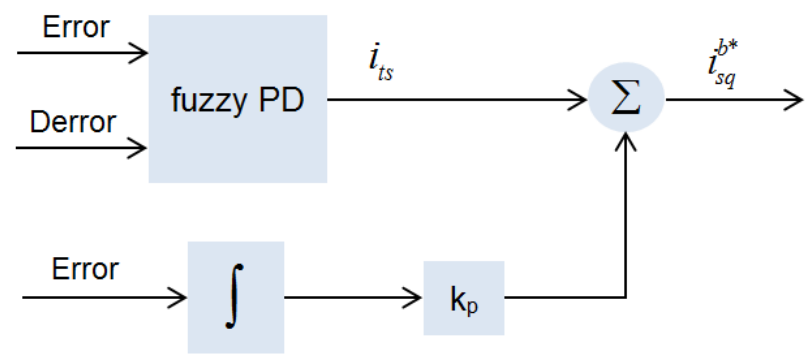

Figure 3. Speed fuzzy controller

The input variables Error and Derror are defined in the fuzzification step. Error is the difference between the reference value and the value of the rotational speed of rotor $\omega_{r}$, and Derror is the derivative of this error. The universes of discourse of Error and Derror comprise a normalized range of -1 to 1 .

Each variable, Error and Derror, consists of seven pertinence functions with triangular and trapezoidal shapes, called: negative big (NB), negative medium (NM), negative small (NS), almost zero (AZ), positive small (PS), positive medium (PM) and positive big (PB). The arrangements of linguistic terms of the Error and Derror are presented in Figure 4 and Figure 5, respectively, in their universes of discourse.

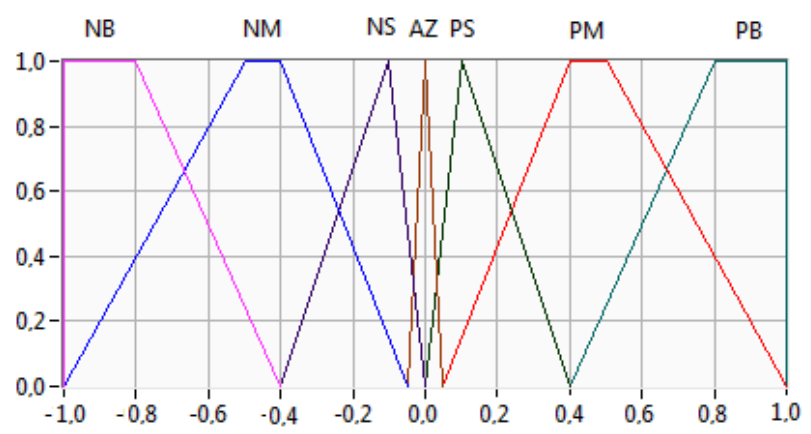

Figure 4. Pertinence functions of the input variable Error

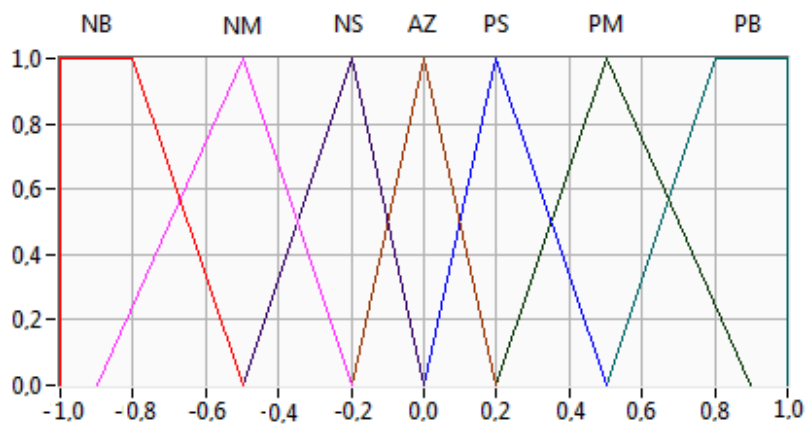

Figure 5. Pertinence functions of the input variable Derror

In fuzzy inference step, the forty-nine control rules developed are inserted in Table 1. For the composition of each rule and the relationship between them, it was applied the max-min inference technique. So, to model each sentence was used $\min$ and the relationships between rules were modeled by applying max. 
International Journal of Artificial Intelligence \& Applications (IJAIA) Vol. 6, No. 4, July 2015

Table 1. Table of fuzzy rules.

\begin{tabular}{|l|l|l|l|l|l|l|l|}
\hline Error & NB & NM & NS & AZ & PS & PM & PB \\
\hline NB & iNB & iNB & iNB & iNB & iPM & iPB & iPB \\
\hline NM & iNB & iNB & iNB & iNM & iPS & iAZ & iPB \\
\hline NS & iNB & iNB & iNM & iNS & iAZ & iPS & iPM \\
\hline AZ & iPB & iPM & iPS & iAZ & iNS & iNM & iNB \\
\hline PS & iNM & iNS & iAZ & iPS & iPM & iPB & iPB \\
\hline PM & iNB & iAZ & iNS & iPM & iPB & iPB & iPB \\
\hline PB & iNB & iNB & iNM & iPB & iPB & iPB & iPB \\
\hline
\end{tabular}

In Figure 3, it can be observed that PD fuzzy generates the $i_{t s}$ output variable in the stage of defuzzification. At this stage, a linear and time-invariant model is determined using TakagiSugeno fuzzy method [18].

The $i_{t s}$ variable is obtained by a weighted average in Eq. (1), in which the terms $i_{t s x}, i_{t s y}$ and $i_{t s z}$ are expressed by Eq. (2), Eq. (3) and Eq. (4), respectively. This equation consists of linear functions defined from the consequents of the control rules and of the numerical values of the input variables Error and Derror.

$$
\begin{gathered}
i_{t s}=\frac{i_{t s x}+i_{t s y}+i_{t s z}}{i N B+i N M+i N S+i A Z+i P B+i P M+i P S} \\
i_{t s x}=i N B(0.5 \times \text { Error }-0.1 \times \text { Derror })+i N M(0.2 \times \text { Error }-0.3 \times \text { Derror })+i N S(0.1 \times \text { Error }-0.5 \times \text { Derror }) \\
i_{t s y}=i A Z(0.2 \times \text { Error }-1.0 \times \text { Derror }) \\
i_{t s z}=i P B(0.5 \times \text { Error }-0.1 \times \text { Derror })+i P M(0.2 \times \text { Error }-0.3 \times \text { Derror })+i P S(0.1 \times \text { Error }-0.5 \times \text { Derror })
\end{gathered}
$$

From the complex model of representation of a three-phase induction machine, the current controller was developed applying the control quadrature with referential in rotor flux $(b)$.

By performing mathematical simplifications, the transfer function used in the current controller project was obtained according to Eq. (5), where $I_{s}^{b}$ and $V_{s}^{b^{\prime}}$ correspond to the stator current and the stator voltage of the three-phase induction motor in the referential of the rotor flux, respectively. The motor parameters constituted Eqs. (6) and (7), in which $l_{s}$ is the cyclic stator inductance, $l_{r}$ is the cyclic rotor inductance, $l_{m}$ is the cyclic mutual inductance, $R_{s}$ is the stator resistance and $\tau_{r}$ is the rotor time constant.

$$
\begin{gathered}
I_{s}^{b}=\frac{l_{r} \sigma}{(s+\eta)} V_{s}^{b^{\prime}} \\
\sigma=\frac{1}{l_{s} l_{r}-l_{m}^{2}} \\
\eta=l_{r} \sigma R_{s}+\frac{\sigma l_{m}^{2}}{\tau_{r}}
\end{gathered}
$$

PI classical controller was used to project the current controller with gains $k_{p_{i}}$ and $k_{i_{i}}$. The gain $k_{p_{i}}$ was determined by Eq. (8), in which $T_{v}$ is the time constant of the voltage source. The gain $k_{i_{i}}^{p_{i}}$ was determined by Eq. (9). 
International Journal of Artificial Intelligence \& Applications (IJAIA) Vol. 6, No. 4, July 2015

$$
\begin{aligned}
& k_{p_{i}}=\frac{1}{4 T_{v} l_{r} \sigma} \\
& k_{i_{i}}=\eta k_{p_{i}}
\end{aligned}
$$

\subsection{Estimation System}

The complex model of representation of the three-phase induction machine was applied for the development of the estimation project of the electromagnetic torque of the three-phase induction motor, using control quadrature with fixed reference in the stator (a) and applying an ANN of the LMS algorithm type.

Initially, for the estimation of the electromagnetic torque, it was estimated the stator flux of the three-phase induction motor.

By applying the voltage model of the machine, in the direct field orientation with reference by the stator flux, it is obtained the estimated stator flux $\lambda_{s}^{a}$ by integrating of the counterelectromotive force. From Eqs. (10) and (11) the stator flux in the $d$ and $q$ components are determined, respectively. The variables of stator voltage $\mathbf{V}_{s}^{a}$ and stator current $\mathbf{i}_{s}^{a}$ were obtained from the motor terminals. The stator resistance $R_{s}$ is considered constant and equal to $49.40 \Omega$.

$$
\begin{aligned}
& \lambda_{s d}^{a}=\int\left(v_{s d}^{a}-R_{s} i_{\mathrm{sd}}^{a}\right) d t \\
& \lambda_{s q}^{a}=\int\left(v_{s q}^{a}-R_{s} i_{\mathrm{sq}}^{a}\right) d t
\end{aligned}
$$

Due to the occurrence of continuous current levels, called offset, in measuring voltages and currents of the motor, caused by the analog components and by the amplifier circuits constituting the voltage and current sensors, offset arose in sign of the counter-electromotive force.

To the elimination of offset in this signal, it was developed a neural adaptive filter, by the technique of LMS algorithm. A neural structure was implemented for each component of the counter-electromotive force, $d$ and $q$, similarly.

In Figure 6, this structure is shown for the component $d$, consisting of only one neuron and one bias as synaptic weight, with constant input equal to 1 . The neural structure had as input the counter-electromotive force $u_{s d}^{a}$ and in the output was obtained the filtered counter-electromotive force $u_{s d f}^{a}$.

The procedure of integrating the filtered counter-electromotive force $u_{s d f}^{a}$ originates offset in the estimation of the stator flux, resulting in an estimation of the electromagnetic torque with not tolerable errors.

For the elimination of the offset in the signal of the estimated stator flux, it was implemented a neural structure for each flux component, $\lambda_{s d}^{a}$ and $\lambda_{s q}^{a}$, analogously. In Figure 7, it is shown a LMS adaptive filtering of $\lambda_{s d}^{a}$, obtaining at the output the estimated stator flux filtered $\lambda_{s d f}^{a}$. 


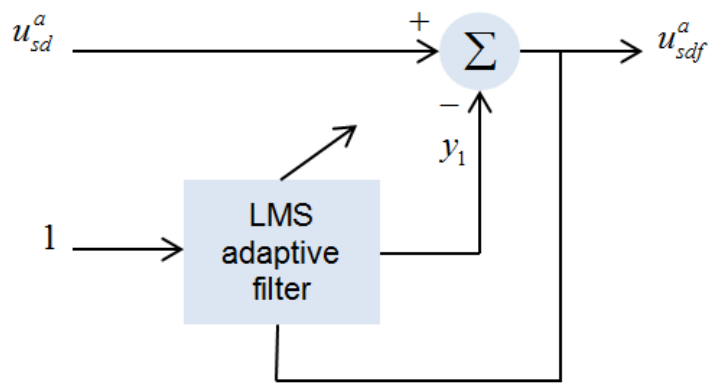

Figure 6. LMS adaptive filtering of the counter-electromotive force

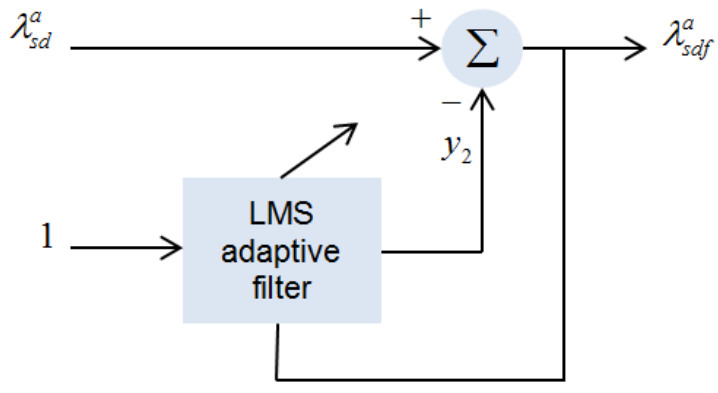

Figure 7. LMS adaptive filtering of the estimated stator flux

The developed algorithm for representation the neural structure to filter the estimated stator flux is described in Eq. (12) and Eq. (13), where $y_{2}(n)$ is the filter output at the current instant and $y_{2}(n+1)$ is the filter output in the next instant. Analogously, the algorithm to filter the counter-electromotive force was implemented. Through these algorithms, an adaptive iteration was effected to each acquisition of the input data.

$$
\begin{gathered}
\lambda_{s d f}^{a}=\lambda_{s d}^{a}-y_{2}(n) \\
y_{2}(n+1)=y_{2}(n)+2 \mu \lambda_{s d f}^{a}
\end{gathered}
$$

In Eq. (13), the learning rates $\mu$ of $0.0001,0.0005$ and 0.001 were used due to the specific feed rates applied for the machinings of steel, brass and nylon, respectively.

After the estimation of the stator flux and the elimination of offsets, it was estimated the electromagnetic torque of the motor of the milling machine using Eq. (14). In this equation, the estimated electromagnetic torque $c e_{\text {est }}$ was determined using the estimated stator flux filtered, the stator current and the constant of the number of pole pairs $P$ of the motor, which is equal to two.

$$
c e_{e s t}=P\left(i_{s q}^{a} \lambda_{s d f}^{a}-i_{s d}^{a} \lambda_{s q f}^{a}\right)
$$

\section{EXPERIMENTAL RESULTS}

To perform the machining of specimens of steel/brass and steel/nylon, the $\mathrm{X}$ base was driven with reference signals of position step type of positive and negative amplitudes, resulting in displacements of this base in right and left directions, respectively, with referential in front of milling machine. 
International Journal of Artificial Intelligence \& Applications (IJAIA) Vol. 6, No. 4, July 2015

From the signal of estimation of the electromagnetic torque of the motor of the $\mathrm{X}$ base in the machining of materials of the specimens, this base was driven with references of specific feed rates.

These references of speed were set for the operational conditions of machining of materials in the milling machine, with a rotation of the cutting tool of $1500 \mathrm{rpm}$, at a cutting depth of $2 \mathrm{~mm}$ in relation to the specimen surface, and work penetration of $6.35 \mathrm{~mm}$, which corresponds to the diameter of the milling cutter. Therefore, for machinings of steel, brass and nylon, the feed rate references set were, in module, $1.6 \mathrm{~mm} / \mathrm{s}, 5.6 \mathrm{~mm} / \mathrm{s}$ and $8.0 \mathrm{~mm} / \mathrm{s}$, respectively.

In Table 2, the average values of estimated electromagnetic torques $c e_{e s t}$ and the respective feed rate references $v^{*}$ of the $\mathrm{X}$ base are presented.

In this table, in steel machining, the average values of torque $c e_{\text {est }}$ of $0.42 \mathrm{Nm}$ and of $-0.17 \mathrm{Nm}$ were verified when driving the $\mathrm{X}$ base to the right and to the left, respectively.

Table 2. Estimated electromagnetic torques and reference speeds.

\begin{tabular}{|l|l|l|l|}
\hline Displacement direction & Material & $\boldsymbol{c e}_{\text {est }}(\mathbf{N m})$ & $\boldsymbol{v}^{*}(\mathbf{m m} / \mathbf{s})$ \\
\hline right & steel & 0.42 & 1.6 \\
\hline right & brass & 0.90 & 5.6 \\
\hline left & steel & -0.17 & -1.6 \\
\hline left & nylon & -0.22 & -8.0 \\
\hline
\end{tabular}

At the initial instant operating of the system, the specimens were positioned $4 \mathrm{~mm}$ to $6 \mathrm{~mm}$ away from the milling cutter. The system was driven on empty since the departure of the system until the specimen reaches the milling cutter.

\subsection{First Experiment}

Initially, the curves of response and of reference of the position variable of the $\mathrm{X}$ base are presented in Figure 8. In this test, the $X$ base was driven with a reference signal of step type with amplitude of $77 \mathrm{~mm}$, performing the machining of the steel/brass specimen. By analyzing the response curve obtained, there was a settling time of $32.36 \mathrm{~s}$, a steady-state error of $0.12 \%$ and non-occurrence of overshoot.

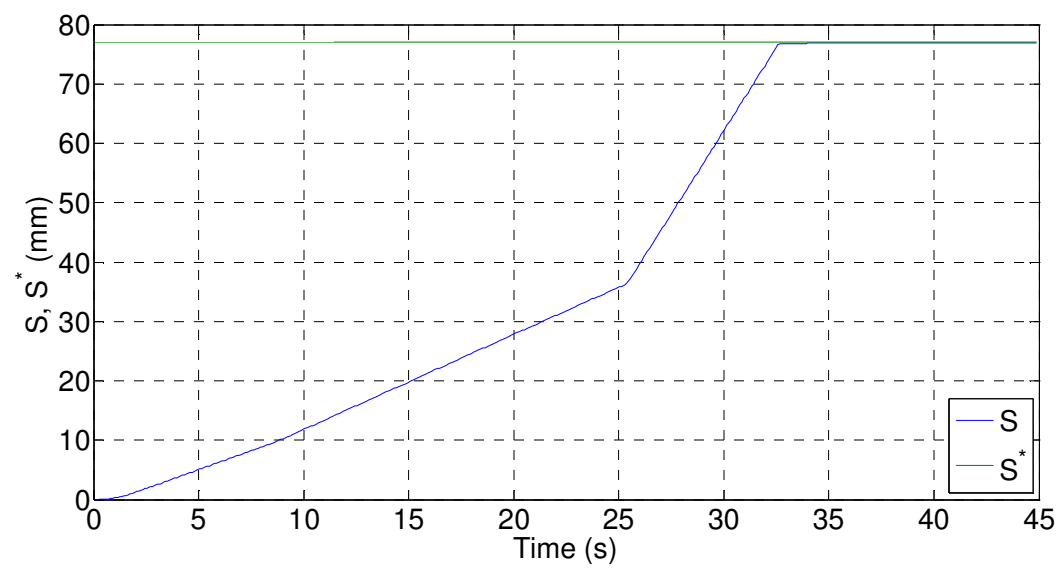

Figure 8. Response and reference curves of the position of $\mathrm{X}$ base 
Then, in Figure 9, the reference curve of feed rate of the X base and the response curve obtained are presented. As the system functioned initially empty, to drive the $\mathrm{X}$ base was applied a signal of the type speed ramp with amplitude of $1.28 \mathrm{~mm} / \mathrm{s}$, keeping constant speed until the instant of $8.64 \mathrm{~s}$.

From this instant, due to the estimation of the electromagnetic torque obtained in steel machining, a speed ramp with amplitude of $1.6 \mathrm{~mm} / \mathrm{s}$ was observed at an interval of $0.1 \mathrm{~s}$ and remained constant until $25.29 \mathrm{~s}$. At that instant, a speed ramp with amplitude of $5.6 \mathrm{~mm} / \mathrm{s}$ was verified at an interval of $0.1 \mathrm{~s}$, due to the estimated electromagnetic torque obtained in the brass machining, and the speed remained constant until a driving $v^{*}$ by null value, resulting thereby in the braking of the $X$ base. Based on the analysis of Figure 9, there were null steady-state errors, in the time intervals in which speed references were constants, and non-occurrence of overshoots.

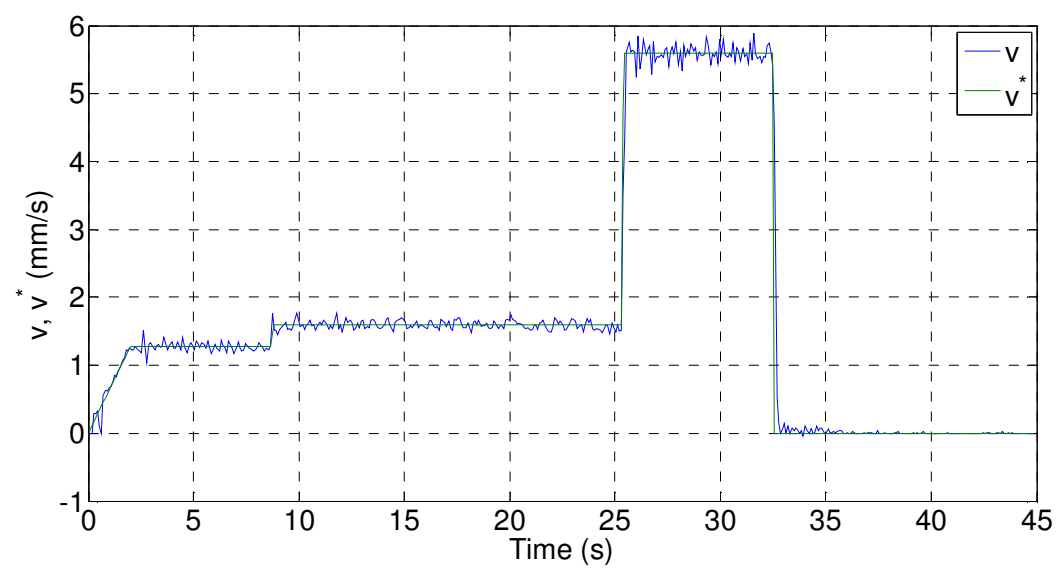

Figure 9. Response and reference curves of the feed rate of $\mathrm{X}$ base

For analysis of neural estimation of the electromagnetic torque of the three-phase induction motor of the $\mathrm{X}$ base, in Figure 10, a curve of the estimated electromagnetic torque $c e_{\text {est }}$ obtained in the machining of the steel/brass specimen was observed. In this graph, it was verified an average value of torque $c e_{e s t}$ of $0.42 \mathrm{Nm}$ in steel machining, in the range of $8.64 \mathrm{~s}$ to $25.29 \mathrm{~s}$, and an average value of $c e_{e s t}$ of $0.90 \mathrm{Nm}$ in the brass machining, in the range of $25.29 \mathrm{~s}$ to $32.49 \mathrm{~s}$.

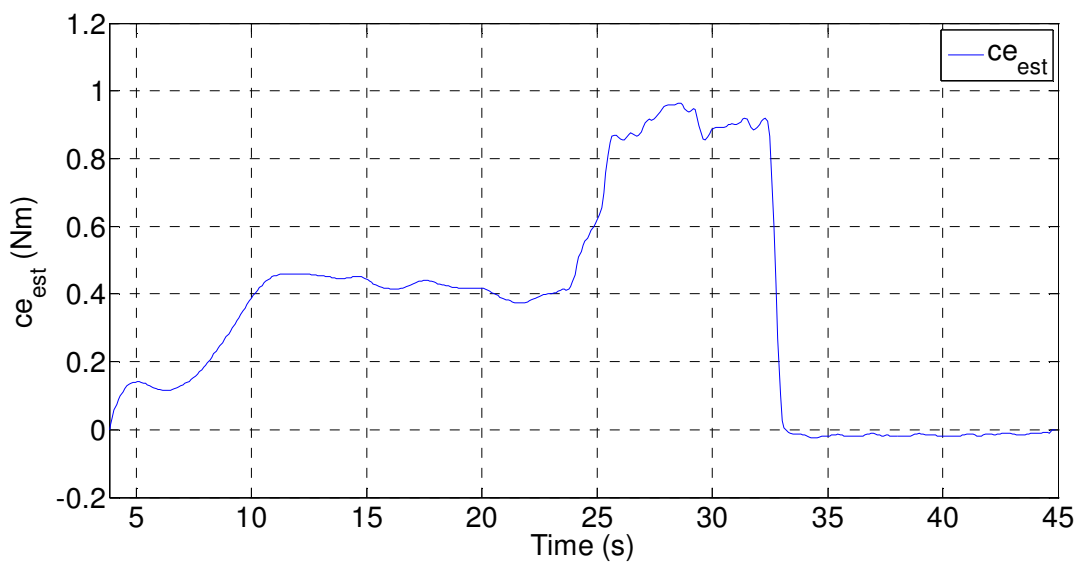

Figure 10. Curve of the estimated electromagnetic torque 


\subsection{Second Experiment}

For machining the steel/nylon specimen, the $\mathrm{X}$ base was driven with a reference signal of step type with amplitude of $-46 \mathrm{~mm}$, as shown in the response and reference curves of the position of $\mathrm{X}$ base in Figure 11. In this graph, there was a settling time of $24.76 \mathrm{~s}$, a steady-state error of 0.20 $\%$ and non-occurrence of overshoot.

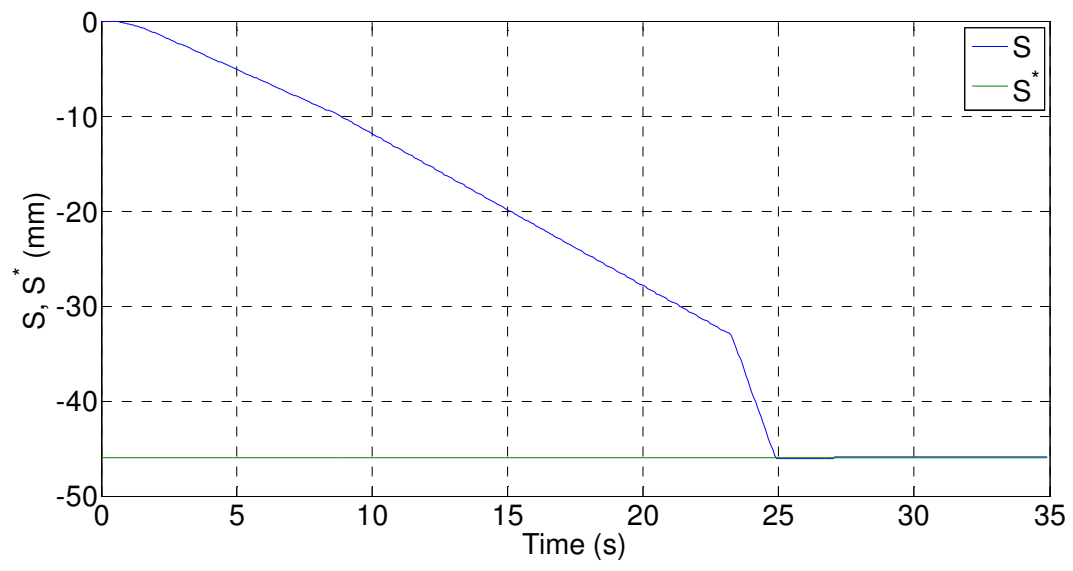

Figure 11. Response and reference curves of the position of $\mathrm{X}$ base

In Figure 12, the reference curve of the feed rate of $\mathrm{X}$ base and the response curve obtained are presented. Initially, it was observed a signal of the type speed ramp with amplitude of -1.28 $\mathrm{mm} / \mathrm{s}$, keeping this speed constant. At the instant of $8.68 \mathrm{~s}$, due to the torque $c e_{\text {est }}$ obtained in the steel machining, there was a speed ramp with amplitude of $-1.6 \mathrm{~mm} / \mathrm{s}$, which remained constant until $23.17 \mathrm{~s}$. From this instant, it was verified a speed ramp with amplitude of $-8.0 \mathrm{~mm} / \mathrm{s}$, due to the torque $c e_{\text {est }}$ obtained in the nylon machining, and this amplitude remained constant until reaching the desired position. By the analysis of Figure 12, there were null steady-state errors, in the time intervals in which speed references were constants, and non-occurrence of overshoots.

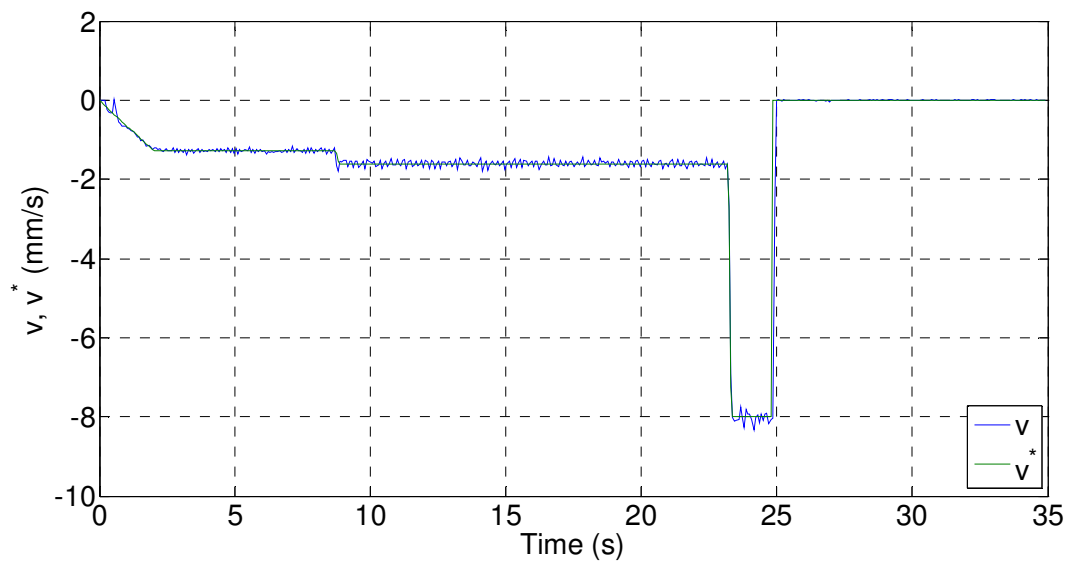

Figure 12. Response and reference curves of the feed rate of $\mathrm{X}$ base

In Figure 13, the curve of the estimated electromagnetic torque of the motor of $\mathrm{X}$ base is presented in the machining of the steel/nylon specimen. In this graph, it was observed an average value of $c e_{e s t}$ of $-0.17 \mathrm{Nm}$ in steel machining, in the range of $8.68 \mathrm{~s}$ to $23.17 \mathrm{~s}$, and an average value of $c e_{\text {est }}$ of $-0.22 \mathrm{Nm}$ in the nylon machining, in the range of $23.17 \mathrm{~s}$ to $24.78 \mathrm{~s}$. 


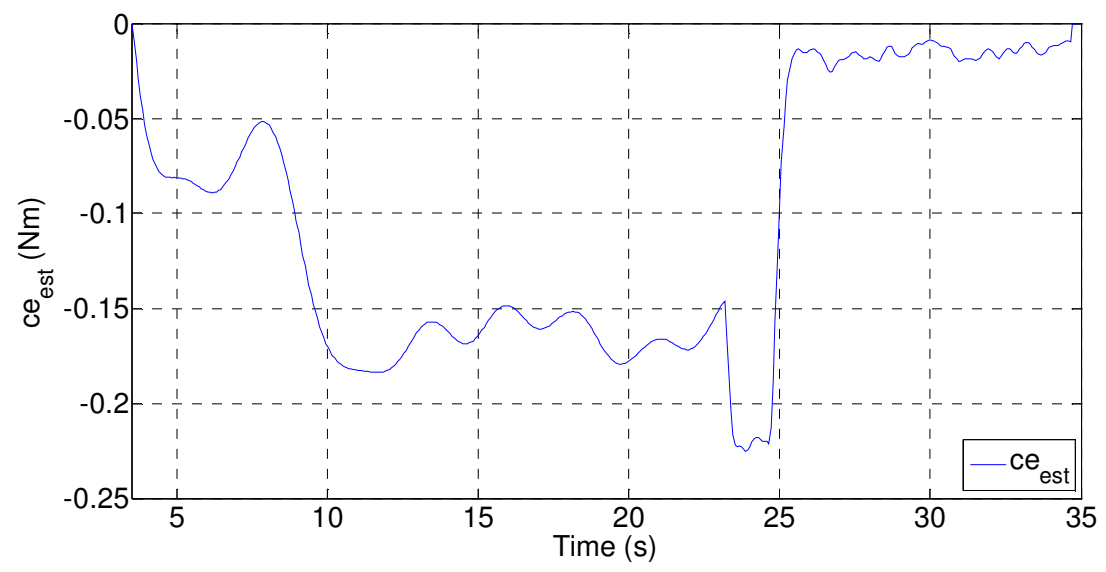

Figure 13. Curve of the estimated electromagnetic torque

\section{Conclusions}

In this work, the controls of position and of feed rate of a milling machine were presented applying, automatically, specific feed rates when machining the materials.

Through the response curves of the two experiments, for position, it was verified a maximum steady-state error of $0.20 \%$, with no overshoots in any of the machining processes. By observing the feed rate curves, the fuzzy controller provided the obtaining of null steady-state errors in both experiments, in the intervals driving with constant speeds, not occurring overshoots.

The modeling of the speed controller by Takagi-Sugeno fuzzy technique made possible the feed rate control not only in the machining of hard materials, such as steel and brass, but also in the machining of soft material, such as nylon, controlling this speed in permanent and transient regimes, when changing from one type of material to another.

The applications of the neural technique of LMS algorithm in the estimations of the stator fluxes possibilited estimate the electromagnetic torques of the motor of the milling machine simply and effectively. In the estimations of torque, the convergence of the two $c e_{\text {est }}$ signals was observed.

Through the performances of machining processes carried out, it was verified the functionality and effectiveness of the developed control strategy. Once, from the estimation of the electromagnetic torque of the milling machine motor in the machining of the specimen materials, it was possible to machine each material with specific feed rate for its cut.

As the results obtained were coherent, presenting the expected performances, it is concluded that the control strategy developed for milling machine of this work was very effective in the machining of different types of materials in the same process.

A perspective for future work is to develop a strategy for the controls of cutting speed and of feed rate of a machining system, allowing machining, continuously, a piece constituted by different types of materials. 
International Journal of Artificial Intelligence \& Applications (IJAIA) Vol. 6, No. 4, July 2015

\section{REFERENCES}

[1] C. E. Stemmer, Cutting Tools I, 5th ed., Florianópolis, SC, Brazil: Publisher UFSC, 2001.

[2] B. U. Guzel, and I. Lazoglu, "Increasing productivity in sculpture surface machining via off-line piecewise variable feedrate scheduling based on the force system model", International Journal of Machine Tools \& Manufacture, vol. 44, pp. 21-28, 2004.

[3] H. Saglam, S. Yaldiz, and F. Unsacar, "The effect of tool geometry and cutting speed on main cutting force and tool tip temperature", Materials and Design, Konya, Turkey, vol. 28, pp. 101-111, 2007.

[4] L. Mao-Yue, F. Hong-Ya, L. Yuan, et al., "An intelligent controller based on constant cutting force for 5-axis milling", IEEE Computer Society, International Conference on Information Technology and Computer Science, pp. 237-241, 2009.

[5] Y. Wang, L. Xiao, S. Zeng, et al., "An optimal feedrate model and solution for high-speed machining of small line blocks with look-ahead”, University of Shanghai Jiaotong, Shanghai, China, 2004.

[6] Q. Li, and X. Yin, "Study on adaptive control method of feedrate based on CAM", IEEE Institute of Electrical and Electronics Engineers, 2010.

[7] J. A. T. Altuna, "Implementation of the direct method of vector control of an induction motor with stator flux orientation using DSP”, M.S. thesis, State University of Campinas, Campinas, SP, Brazil, 1997.

[8] C. O. Affonso, "Neural networks applied in wood machining processes", Ph.D. dissertation, Faculty of Engineering of Campus Guaratinguetá, Paulista State University, Guaratinguetá, SP, Brazil, 2013.

[9] L. A. Mozelli, "Fuzzy control for Takagi-Sugeno systems: improved conditions and applications", M.S. thesis, Federal University of Minas Gerais, Belo Horizonte, MG, Brazil, 2008.

[10] I. S. Shaw, and M. G. Simões, Control and Modelling Fuzzy, São Paulo, SP, Brazil: Publisher Edgard Blucher Ltda, 2004.

[11] H. Huang, A. Li, and L. Xu, "Fuzzy control of milling process with constraint of spindle power", IEEE - Proceedings of the 7th World Congress on Intelligent Control and Automation, pp. 7936 7939, 2008.

[12] Z. Miao, and W. Li, "A fuzzy system approach of feed rate determination for CNC milling”, IEEE Institute of Electrical and Electronics Engineers - ICIEA, pp. 1911-1916, 2009.

[13] A. Nigrini, Neural Networks for Pattern Recognition, Cambridge, England: The MIT Press, 1993.

[14] S. Haykin, Adaptive Filter Theory, New Jersey, United States: Prentice Hall International, 1991.

[15] B. Widrow, J. R. Glover Jr., J. M. Mccool, et al., "Adaptive noise canceling: principles and applications", IEEE Institute of Electrical and Electronics Engineers, vol. 63, no. 12, pp. 1692, 1975.

[16] K. M. Dobrowolski, "Noise filtering on solar bursts spectrum using Adaline neural network", M.S. thesis, National Institute for Space Research, São José dos Campos, SP, Brazil, 2009.

[17] H. V. D. Linden Filho, "Application of an adaptive neural filter network in order to cut off the DC component to estimate the electromagnetic torque of three-phase induction motors", M.S. thesis, Federal University of Paraíba, João Pessoa, PB, Brazil, 2012.

[18] C. E. Milhor, "Otto cicle engine idle speed Hळ Takagi-Sugeno fuzzy control”, Ph.D. dissertation, School of Engineering of São Carlos, University of São Paulo, São Carlos, SP, Brazil, 2008. 